\title{
Produções midiáticas contemporâneas e a ampliação dos limites da tradução
}

\author{
Maria Clara Castellões de Oliveira*
}

A Biagio D'Angelo

\begin{abstract}
Apresentação
"Tradução e Movimento", título da terceira edição do simpósio nacional do grupo de pesquisa MultiTrad - Abordagens Multidisciplinares da Tradução, atraiu-me desde quando dele tomei conhecimento, pois ele, assim como as palavras "tradução" e "movimento", tomadas em separado, me pareceram muito condizentes com o que acontecia à minha volta, em termos tanto pessoais quanto profissionais. Naquele momento, eu ocupava um entrelugar, tendo um pé na universidade e outro fora dela. Embora estivesse de licença, ainda continuava orientando monografias de conclusão de curso de alunos do Bacharelado em Letras: Ênfase em Tradução - Inglês da Universidade Federal de Juiz de Fora. Desse modo, ao mesmo tempo em que procurava me comportar como alguém descompromissada com as atividades profissionais, permitindo-me, entre outras coisas mais comezinhas, assistir televisão, via-me comprometida com meus orientandos e corrigia, incessantemente, as diversas versões que me enviavam do material que produziam.
\end{abstract}

O que conduzia um universo ao outro era a percepção, proveniente das novelas que assistia e de um dos trabalhos que orientava, de que: 1) a tradução - a sua ética - estava, finalmente, dando sinais de possibilidades de movimento; 2) os consumidores de tradução já não eram mais tão ingênuos quanto o foram, transformando-se, eles próprios, muitas vezes, em autores das traduções que gostariam de consumir, e 3) esses sinais provi-

${ }^{*}$ Universidade Federal de Juiz de Fora. 
nham de produções de duas das mais poderosas mídias existentes: a televisão e a Internet.

A tarefa de revelar essas percepções, extraídas de meu trânsito entre os universos pessoal e profissional, aos colegas do MultiTrad, grupo, que, em seus primórdios, se reuniu, precipuamente, em torno da pesquisa sobre tradução e ética, pareceu-me, pois, inescapável. Afinal, em algumas ocasiões eles tinham me ouvido não apenas reivindicar uma interação maior entre a academia e a sociedade, a fim de evidenciar a força da tradução e do tradutor na alteração, formação e consolidação de identidades culturais, ${ }^{1}$ como também conclamar os profissionais que atuam na academia e os que exercem suas atividades fora dela a se unirem "no sentido não só de criarem estratégias que imprimam maior visibilidade à tradução e à classe dos tradutores, como também, sobretudo, de sensibilizarem a sociedade em geral para as questões éticas que envolvem a tradução" (Oliveira 2011, p. 99). ${ }^{2}$

O trabalho que se segue é, portanto, uma reflexão - ainda em processo de construção - acerca dos movimentos que, no âmbito de produções midiáticas, podem vir a ter influência sobre a prática da tradução literária, pois, no caso das novelas, elas se valem de procedimentos de tradução que não escamoteiem a proveniência distante ou estrangeira de seus personagens, e, no caso das legendas feitas e disponibilizadas na Internet, elas alargam os limites da legendagem, uma vez que se pautam em procedimentos que, consciente ou inconscientemente, se aproximam da tradução da letra,

\footnotetext{
${ }^{1}$ Refiro-me ao artigo “Questões Éticas e Políticas em Torno da Tradução Literária”, de 2009, publicado no volume 7 de Tradução em Revista. Disponível em <http://www.maxwell.vrac.pucrio.br/trad_em_revista. php? strSecao=input0 $>$. Esse artigo foi apresentado, de forma modificada, no $X$ Encontro Nacional de Tradutores e IV Encontro Internacional de Tradutores, organizados pela Associação Brasileira de Pesquisadores em Tradução e pela Universidade Federal de Ouro Preto, em setembro de 2009, e na II Semana de Letras da Faculdade de Letras da Universidade Federal de Juiz de Fora, ocorrida em outubro de 2009.

2 Refiro-me ao artigo “A Construção das Éticas de Tradução de Textos Literários a partir da Experiência: A Interação entre a Academia e a Sociedade", publicado no volume 31 da Gragoatá. Disponível em <http://www.uff.br/revistagragoata/revistas/gragoata31web.pdf>. Ele foi apresentado em simpósio organizado pelo MultiTrad no contexto do XII Congresso Internacional da Associação Brasileira de Literatura Comparada, ocorrido em julho de 2011, na UFPR.
} 
tal como a defendeu Antoine Berman em A Tradução e a Letra ou o Albergue do Longínquo (2007 [1985]). ${ }^{3}$

\section{As novelas de TV}

As novelas, principalmente as produzidas pela Rede Globo, são o principal produto midiático brasileiro consumido no exterior.

Geração Brasil, novela produzida pela Rede Globo e de autoria de Filipe Miguez e Izabel de Oliveira, foi ao ar entre maio e outubro de 2014, às 19 horas. Desde o seu início, ela chamou atenção pelas características linguísticas de personagens como Shin-Shoo, Manu, Maria Vergara e Pamela e Megan Lily Parker-Marra, representadas respectivamente por Rodrigo Pandolfo, Chandelly Braz, Débora Nascimento, Claudia Abreu e Isabelle Drummond. Essas cinco personagens, a primeira, proveniente da Coréia do Sul; a segunda, original do Recife, a terceira, mexicana, e as duas últimas, nascidas e criadas nos EUA, possuíam sotaques fortes, que remetiam a seus lugares de origem. As falas do personagem sul-coreano apontavam para a dificuldade que os cidadãos desse país possuem de emitirem o som da letra " $r$ ", pronunciada como se fosse um " 1 " (/l/). Chandelly Braz, a Manu, que foi para Pernambuco ainda bebê e lá viveu por mais de 20 anos, ao contrário do que aconteceu em Cheias de Charme, novela escrita pelos mesmos autores de Geração Brasil, não fez o menor esforço para disfarçar o seu sotaque. Por sua vez, Maria Vergara, que morreu logo no início da trama, falou o tempo todo em espanhol.

\footnotetext{
3 Produzi nos últimos anos artigos nos quais procurei pensar a ética da tradução a partir de filmes realizados para a tela grande. Nesse sentido, menciono: 1) A Tradução e a Ética da Responsabilidade em Períodos Ditatoriais (In: OLIVEIRA, Maria Clara Castellões de; LAGE, Verônica Lucy Coutinho. (Orgs.). Literatura, crítica, cultura I. Juiz de Fora: Editora UFJF, 2008. p. 193-203), no qual trabalhei com o filme A Vidas dos Outros, do alemão Florian Henckel von Donnersmarck; 2) A Ética do Escritor, do Cineasta e do Tradutor na Cena Pós-moderna (In: GONÇALVES, Ana Beatriz Rodrigues; CARRIZO, Silvina Liliana; LAGE, Verônica Lucy Coutinho (Orgs.). Literatura, crítica, cultura III. Juiz de Fora: Editora UFJF, 2009. p. 161-169), em que discuti o filme Ninho Vazio, do cineasta argentino Daniel Burman; 3) A Tradução e a Ética do Para o Outro: E Agora, Aonde Vamos? ( In: ESTEVES Lenita; VERAS, Viviane (Orgs.). Vozes da tradução, éticas do traduzir. São Paulo: Humanitas, 2014. p. 53-66), em que trato do filme cujo nome é mencionado no título do artigo, da cineasta franco-libanesa Nadine Labaki, e 4) Questões de Tradução, Literatura e Cultura a partir de Cópia Fiel, de Abbas Kiarostami, apresentado no 4º. Simpósio Internacional de Letras Neolatinas da UFRJ, intitulado: “Livro, Leitor, Leitura - Desafios para as Letras - (Colóquio em Homenagem a Théophile Gautier)”, em setembro de 2011, ainda não publicado.
} 
Tratamento semelhante vinha sendo dado aos personagens de Meu Pedacinho de Chão. De autoria de Benedito Rui Barbosa e transmitida pela Rede Globo às 18 horas, entre 7 de abril e 1o․ de agosto de 2014, essa novela, uma fábula que se passava em um tempo e um local inventados, também teve personagens que falavam com sotaque. Além de pronunciarem fortemente a letra " $r$ ", esses personagens imprimiram um ritmo e uma velocidade próprios ao que enunciavam.

Foram diversas as posturas da imprensa com relação às especificidades linguísticas encontradas nessas duas produções. Em 14 de maio de 2014, Patrícia Kogut, autora da coluna que leva o seu nome no "Segundo Caderno" de O Globo, deu nota zero "para o sotaque carregado de vários personagens de 'Geração Brasil'”. Em suas palavras, "aquilo funciona como uma interferência meio chata, um falsete. Que eles aprendam rápido o português" (p. 8).

Se assim pensava Kogut, uma espectadora competente, de outra forma não poderiam pensar milhões de outros espectadores, dispersos pelo Brasil afora e não tão competentes assim, acostumados a ouvirem personagens indianos e turcos (vide, respectivamente, as novelas Caminho das Índias e Salve Jorge, de Glória Perez) falando português em seus países de origem e no âmbito de suas famílias sem qualquer sotaque, apenas uma vez ou outra incorporando expressões das línguas hindu e turca a suas falas.

Naquele momento, por exemplo, estava no ar Em Família, novela de autoria de Manoel Carlos e transmitida às 21 horas pelo mesmo canal de televisão. Essa novela não teve qualquer preocupação em caracterizar seus personagens em função de sua origem geográfica. Praticamente todos os personagens de suas primeira e segunda fases residiam em Goiânia e não houve sequer um deles que se valesse de uma linguagem ou de uma entonação próximas às dos goianos. Quando se mudaram para o Rio de Janeiro, na terceira e última fase da novela, é como se tivessem morado lá - ou pelo menos na região sudeste do país - desde sempre.

Quatro dias depois da nota publicada por Kogut, a matéria de capa da "Revista da TV", também de O Globo, que teve por título "Linguagem Universal", abordou o tratamento que vinha sendo dispensado à linguagem em Geração Brasil e Meu Pedacinho de Chão, sem, contudo, emitir um 
juízo de valor no que diz respeito a esse tipo de escolha. Na verdade, segundo a jornalista Natalia Castro, autora da matéria, em referência a Geração Brasil, “[...] a variedade sonora é uma das grandes marcas da novela das $19 h^{\prime \prime}$ (p. 12). Os autores da novela, convidados a se posicionarem sobre o assunto, foram unânimes em reconhecerem que a sua obra se especifica em função do entrecruzamento dessas diversas formas de falar. Para Izabel de Oliveira "o sotaque ajuda a legitimar os personagens. É uma ferramenta poderosa que o autor tem para criar personagens" (p. 12-13). Por sua vez, Filipe Miguez, nas palavras da jornalista, disse acreditar que "as variadas sonoridades dão credibilidade ao texto e à história que está sendo contada" (p. 13). Em relação a Meu Pedacinho de Chão, seu diretor, Luiz Fernando Carvalho, afirmou que essa telenovela não tinha compromisso com uma realidade linguística específica: "não é um sotaque realista. Afinal, trata-se de um mundo inventado, logo, a linguagem tem de ser inventada também" (p. 13).

Izabel Ribeiro, referindo-se especificamente a Geração Brasil, contudo, fez menção àquilo que, a meu ver, mais se destacava na novela que escreveu em parceria com Filipe Miguez e em Meu Pedacinho de Chão: a mistura de vozes, expressões e gírias, que, em sua opinião, seria "o que há de mais rico na telenovela" (p. 12-13). Nesse sentido, merecem destaque, na primeira novela, os personagens Pamela e Megan Lily Parker-Marra, mãe e filha, que frequentemente salpicavam suas falas com palavras (dear, darling, whatever, like), expressões (Brazilian wax) e frases ("It's marvelous. I love capoeira.") em língua inglesa.

Pamela, mais especificamente, vez por outra cometia não apenas gafes, ao se referir a aspectos da cultura brasileira ("Quero conhecer o Brasil todo: do Rio Grosso do Norte até o Mato Grande do Sul”; “[...] quando o Amazonas encontra o mar e faz uma perereca...", "Quero ajudar os imigrantes da seca do Pantanal." - meus grifos), como também ao tentar utilizar construções idiomáticas da língua portuguesa ("Logo você vai estar com a faca e o peixe na mão"; "A festinha está tudo de bem!", "Jonas são águas viradas"; "Depois que viemos para o Brasil, eu tenho feito vista gorda para muitas coisas"- meus grifos). Ela também cometia erros na tradução de algumas palavras ("Vocês, brasileiros, são muito conservativos" - meu grifo), na op- 
ção pelo uso da tradução literal quando a acepção da palavra era outra ("Nós temos que dar a ela o nosso suporte" - meu grifo) e no uso de palavras cujos sons são semelhantes aos daquelas que, de fato, deveriam ser utilizadas ("Depois dos comerciais! Não saia de sua potranca!"; “Prepare-se para uma batedeira de problemas!" - meus grifos).

Na novela das 18 horas, o dono do armazém, Giácomo, representado por Antônio Fagundes, além de utilizar expressões em italiano, emitia frases inteiras nessa língua, por ele mesmo traduzidas/reiteradas em português, enquanto a maior parte dos personagens da novela, moradores de uma cidade interiorana, falava um dialeto caipira. Além de utilizarem "ocês" com frequência, esses personagens se valiam de expressões em desuso - como "pra mor" (por causa de) -, tornando-as compreensíveis em função do contexto em que as inseriam.

Embora muitas das situações descritas tenham fornecido às duas novelas certo humor, o objetivo de seus autores não foi o de fazerem comédia, mas o de evidenciarem aos espectadores que esses personagens têm outras nacionalidades ou moram em regiões do Brasil distantes do eixo Rio-São Paulo e, portanto, falam diferente. Com relação a isso, Filipe Miguez, um dos autores de Geração Brasil, disse que, para ele, "todos os personagens teriam sotaque das regiões do mundo onde moram" (p. 13). No entanto, as justificativas oferecidas pelo diretor de Meu Pedacinho de Chão para as particularidades linguísticas dos personagens dessa novela apontam para a importância de se dar atenção não apenas ao que os personagens falam, como também a como elas falam. Disse ele:

\footnotetext{
A fala está a serviço da compreensão tanto do personagem como do que ele diz. A voz é um dos instrumentos do ator para comunicar o seu personagem, como ele fala é tão importante quanto o que ele fala, pois revela muito de quem ele é, de onde ele vem e para onde quer ir, e isto não só é importante na trama como a enriquece (p. 13, meus grifos).
}

O tratamento dispensado por essas duas produções midiáticas da Rede Globo ao modo de falar de personagens que provêm de lugares onde se fala uma língua ou uma modalidade de língua diferente da considerada padrão no local no qual transcorre a história narrada constitui-se um mo- 
vimento importante em direção à sensibilização dos espectadores brasileiros para a importância de se evidenciar a estrangeiridade do sistema de valores embutidos em produtos culturais que provêm de outro país ou que abordam uma realidade outra, estando, entre esses produtos, a literatura.

\section{As legendas de seriados de TV feitas e disponibilizadas na internet}

Uma das monografias que orientei em 2014, no âmbito do Bacharelado em Letras: Ênfase em Tradução - Inglês da Universidade Federal de Juiz de Fora, dedicou-se a investigar o fenômeno da legendagem realizada na Internet, hoje a mais poderosa das mídias existentes. Essa legendagem é feita, via de regra, por amadores, fãs dos filmes, seriados de TV e videogames que legendam. A primeira monografia produzida sobre esse tema, defendida em 2010, já tornava evidente que esse fenômeno, surgido em meados dos anos 2000, vem expandindo, de várias formas, os limites da legendagem tal como ela vem sendo praticada por profissionais da área e tratada por estudiosos da tradução.

Enquanto a monografia de $2010^{4}$ estabeleceu comparações entre as legendas de episódios The Office encontradas no DVD comercializado da série e as realizadas por seus fãs e disponibilizadas na Internet, em blogs, a de 2014 deteve-se no mesmo tipo de comparação, mas, desta feita, tendo como corpus analítico o primeiro episódio da primeira temporada de Game of Thrones. ${ }^{5}$ A monografia produzida em 2014 salientou o esforço dos legendadores da Internet no sentido de proporcionarem aos consumidores desse produto midiático um acesso cada vez maior às suas particularidades linguísticas e culturais. Na tentativa de cumprirem esse objetivo, eles utilizaram, mesmo que inconscientemente, procedimentos de tradução que tornaram as legendas produzidas mais próximas da letra do original.

A tradução da sentença "The White Walkers, I saw the White Walkers, the White Walkers, I saw them" ilustra o esforço dos legendadores da Internet no sentido de destacarem as particularidades linguísticas presentes no seri-

\footnotetext{
${ }^{4}$ Monografia realizada por Felipe Augusto Noronha e intitulada A legendagem de trechos de episódios da série The Office em língua portuguesa do Brasil encontrada na Internet: nova mídia, novos procedimentos.

${ }^{5}$ Monografia realizada por Fernando Almeida Mendes Duque e intitulada Legendagens comercial e amadora do primeiro episódio da primeira temporada de Game of Thrones.
} 
ado, que, segundo Fernando Duque, autor da monografia, "possui diversas classes de personagens, cada uma com suas características de fala e comunicação" (p. 45). Nesse sentido, ao optarem pela utilização do pronome pessoal do caso reto e não pela do pronome pessoal do caso oblíquo na tradução de "I saw them", os legendadores da Internet evidenciaram a presença dessas superposições de línguas presentes no seriado. Além disso, deve-se destacar que, enquanto os legendadores do DVD traduziram White Walkers como "Os Outros", os da Internet ficaram mais próximos da letra, tendo traduzido o sintagma nominal como "Caminhantes Brancos", a despeito de terem eliminado, por questões técnicas, uma das repetições da expressão (Duque 2014, p. 47-48).

\begin{tabular}{|l|l|l|}
\hline \multicolumn{1}{|c|}{ ORIGINAL } & \multicolumn{1}{c|}{ DVD } & \multicolumn{1}{c|}{ INTERNET } \\
\hline "The White Walkers, I & "Os Outros, eu vi Os & "Os Caminhantes Bran- \\
saw the White Walkers, & Outros, Os Outros, eu & cos, eu vi um deles, Os \\
the White Walkers, I saw & os vi". & $\begin{array}{l}\text { Caminhantes Brancos, eu } \\
\text { vi eles". }\end{array}$ \\
them." & & \\
\hline
\end{tabular}

Quadro 1 - Comparação de legendas de trecho do primeiro episódio da primeira temporada de Game of Thrones encontradas no DVD e na Internet: A tradução de I saw them e de White Walkers. ${ }^{6}$

Outro exemplo citado por Duque, que, de certa forma, se relaciona a aspectos culturais do seriado, refere-se à inserção de informações, que, em um texto literário, poderiam ser colocadas em notas de pé página. No quadro abaixo, extraído da monografia em questão, é possível observar que os legendadores da Internet tentaram precisar a referência geográfica implícita na locução adverbial down here, que acabou se perdendo nas legendas do DVD. Assim, a sentença "They don't belong down here" foi traduzida pelos legendadores da Internet por "Eles não pertencem aqui ao sul" (Duque 2104, p. 49).

\footnotetext{
${ }^{6}$ Quadro modificado a partir de outro, apresentado por Duque (2014, p. 47) em sua monografia.
} 


\begin{tabular}{|l|l|l|}
\hline \multicolumn{1}{|c|}{ ORIGINAL } & \multicolumn{1}{|c|}{ DVD } & \multicolumn{1}{c|}{ INTERNET } \\
\hline "Where will they go? & "Para onde irão? A & "Aonde eles vão? Sua \\
Their mother has died" & mãe deles morreu". & mãe morreu". \\
"They don't belong & "Eles não pertencem & "Eles não pertencem \\
down here." & aqui". & aqui ao sul". \\
"It's better a quick & "É melhor uma morte & "É melhor uma morte \\
death, they won't last & rápida, não sobrevive- & rápida, não sobrevive- \\
without their mother." & rão sem a mãe". & rão sem a mãe". \\
\hline
\end{tabular}

Quadro 2 - Comparação de legendas de trecho do primeiro episódio da primeira temporada de Game of Thrones encontradas no DVD e na Internet: A tradução de down here ${ }^{7}$

A tentativa de viabilizar um acesso maior às particularidades linguísticas e culturais dos originais leva os legendadores da Internet a distenderam as prescrições de ordem técnica que condicionam a atuação dos profissionais que legendam séries comercializadas nos formatos DVD e BluRay e das apresentadas na televisão, principalmente na por assinatura ou fechada.

No primeiro trabalho que orientei sobre esse tipo de legendagem, o seu autor, Felipe Noronha, já chamava a atenção para vários aspectos inovadores desse produto. Utilizando o ensaio de Walter Benjamin “A Obra de Arte na Era de sua Reprodutibilidade Técnica" (1985), no qual o filósofo aponta para o fato de que o meio afeta sobremaneira a forma pela qual uma obra de arte é decodificada, Noronha salientou que os internautas, além de terem adquirido, como usuários dessa mídia e de outras tantas, uma velocidade de leitura maior do que os que estão habituados apenas a assistirem esses filmes na TV, no DVD e/ou no Blu-Ray, têm acesso a ferramentas disponibilizadas pelos seus computadores que lhes permitem retroceder e pausar as imagens a seu bel prazer. Sabendo disso, esses legendadores, no intuito de manterem uma fidelidade maior em relação às peculiaridades linguísticas e culturais presentes nos originais, evitam "a omissão e a generalização, as duas estratégias de tradução mais facilmente encontradas na

\footnotetext{
${ }^{7}$ Quadro modificado a partir de outro, apresentado por Duque (2014, p. 48) em sua monografia.
} 
legendagem [profissional], [...] abrindo espaço para outras estratégias, como a adição, a ramificação e a especificação [...]" (Noronha 2010. p. 36). ${ }^{8}$

Um aspecto interessante do trabalho de Noronha foi o reconhecimento da presença de notas culturais no contexto da legendagem feita na e para a Internet. Uma das notas por ele encontradas em legendas de The Office refere-se à colocação, entre parênteses, de informação sobre quem seria Dale Earnhardt ("piloto lendário da NASCAR"). ${ }^{9}$ Embora, no que diz respeito especificamente a esse exemplo, as legendas do DVD não tenham trazido essa informação, Noronha chama a atenção para o fato de que, muito certamente em função das estratégias de tradução utilizadas pelos legendadores da Internet, legendadores de séries comercializadas nos formatos DVD e Blu-Ray passaram a acrescentar informações que consideram esclarecedoras para os espectadores de seus produtos. Nesse sentido, encontram-se, no trabalho de Noronha, dois exemplos, um extraído das legendas em DVD do filme Junebug (Retratos de Família), de Phil Morrison, e outro, das legendas em Blu-Ray do filme The Full Monty (Ou Tudo ou Nada), de Peter Cattaneo. No primeiro caso, é adicionada uma explicação a respeito de Junebug, nome que seria dado ao bebê da personagem principal do filme. O teor da nota, colocado entre parênteses, foi o seguinte: “joaninha, em inglês". No segundo caso, como diz Noronha,

[...] a nota é utilizada para explicitar o trocadilho presente em uma das piadas. Um dos personagens, fazendo uma audição para participar de um grupo de striptease masculino, se apresenta como Horse. O nome logo ge-

\footnotetext{
${ }^{8}$ Esses procedimentos foram identificados por David Katan, em Translating cultures: an introduction for translators, interpreters and mediators (1999), como sendo os utilizados quando está se lidando com a tradução de dados culturais. A ramificação e a especificação foram traduções oferecidas por Noronha para os termos chunking sideways e chunking down. Diz Noronha a respeito da ramificação: "Segundo Katan, a ramificação implica em "se direcionar para os lados ou lateralmente, de forma muito próxima à de Lateral Thinking [O pensamento lateral] (1970), de Edward de Bono" (Katan 1999, p. 148). Esse procedimento se refere à tentativa de encontrar alternativas na língua de chegada que possam melhor acessar as ideias presentes no texto original. Um exemplo seria substituir poltrona por cadeira ou sofá, que são outros exemplos de mobília utilizados para sentar-se, possibilitando o leitor compreender o que está sendo dito através dessa mediação cultural" (Noronha 2010, p. 23). A especificação, por sua vez, "consiste em 'partir de um conceito mais geral para um mais específico' (Katan 1999, p. 148), ou seja, em encontrar hipônimos que podem gerar informações valiosas sobre as lacunas que precisam ser preenchidas na tradução" (Noronha 2010, p. 23).

${ }^{9}$ NASCAR = National Association for Stock Car Auto Racing (Associação Nacional de Corrida de Stock Car).
} 
ra inquietude entre os outros homens, e um deles diz: "Pergunte pra ele por que se chama 'The Horse' (cavalo)' (2010, p. 34).

Além de estarem contribuindo para a modificação das estratégias utilizadas por profissionais que se dedicam a essa atividade de tradução audiovisual, o fenômeno da legendagem disponibilizadas na Internet vem distendendo as fronteiras entre o tradutor e o seu público, na medida em que o consumidor dos produtos legendados é ele próprio o produtor de legendas. Ainda: a prática da legendagem nesse meio vem concorrendo para que o sentido textual se construa cada vez mais participativamente, inaugurando "espaços discursivos coletivos de traduzibilidade, envolvendo negociações complexas de identidade cultural e de cidadania".${ }^{10}$ Nesse sentido, o trabalho de Duque, ao comentar o funcionamento do programa que, no contexto da Internet, é o mais utilizado para a criação de legendas, o Subtitle Workshop, aborda a presença de uma funcionalidade que permite ao espectador sugerir correções aos legendadores do produto.

\section{Últimas considerações}

Neste momento final de meu trabalho, transcrevo duas opiniões da mesma Patríca Kogut que mencionei logo de seu início. Elas apontam para o poder transformador e educador da televisão e da Internet relativo a questões de tradução. Em 23 de julho de 2014, um pouco mais de dois meses após a primeira nota sobre o incomodo causado pelo sotaque dos personagens de Geração Brasil, a jornalista publicou, na mesma coluna, a seguinte nota, com o título de "Tentando entender":

A Globo fez um novo grupo de discussão de "Geração Brasil" em São Paulo. A novela tinha passado por uma primeira pesquisa antes da Copa.

\footnotetext{
10 Citação retirada do resumo do trabalho "Investigating Digitally Born Translation Agencies in the Context of Popular Culture" ("Investigando Agências de Tradução Nascidas Digitalmente no Contexto da Cultura Popular"), apresentado por Luiz Pérez-González no evento "Researching Translation in the Context of Popular Culture - Theoretical and Methodological Perspectives" ("Pesquisando a Tradução no Contexto da Cultura Popular - Perspectivas Teóricas e Metodológicas"), realizado na Universidade de Manchester em 15 de fevereiro de 2015. Site do evento: < http://artisinitiative.org/2014/11/15/artissymposium/>. Texto original: "[...] the translation of popular culture in the digital context steers us away from the translator as an individual or subject position, and towards collective discursive spaces of translatorship involving complex negotiations of cultural identity and citizenship."
} 
Ela revelou que o público não rejeitava o tema central, a tecnologia, nem o

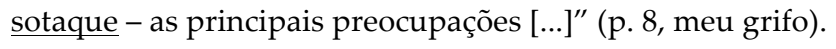

A segunda nota faz referência ao universo da legendagem. Nela, cuja publicação aconteceu em 22 de novembro de 2014, Kogut dava nota 10 "para o GNT por exibir "Curso de culinária do Gordon Ramsay" com o devido respeito à legendagem. A tradução é impecável, fiel aos termos técnicos da atividade è̀s metáforas feitas pelo chef. Uma beleza." (p. 8, meus grifos).

Isso posto, eu terminaria o meu trabalho reconhecendo que o meu trânsito entre os universos pessoal e profissional durante o ano de 2014 permitiu-me observar que a tradução está em movimento. Na verdade, eu diria que ela está prestes a entrar em ebulição. Nos meus sonhos mais selvagens, eu arriscaria dizer que esse movimento, essa quase ebulição, proporcionada por produtores culturais que atuam fora da academia - autores e diretores de novela e espectadores de seriados de TV que se tornaram legendadores dos mesmos no contexto da Internet - está oferecendo uma resposta a nós, pesquisadores da tradução. Embalados pelo conceito de ética, vimos defendendo posturas que hoje são colocadas em prática por esses agentes culturais, que, contando com o apoio das duas das mais poderosas mídias existentes, levam seus produtos a um número cada vez maior de pessoas, que, por sua vez, muito certamente, vão se educando para receberem traduções de textos literários realizadas nos mesmos moldes das novelas e das legendas das séries que aqui discuti: traduções, nos termos de Antoine Berman (2007 [1985]), não mais etnocêntricas, hipertextuais e platônicas, mas éticas, poética e pensantes.

\section{Referências}

BERMAN, Antoine. A tradução e a letra ou o albergue do longínquo. Trad. Maria-Hélène Torres et al. Rio de Janeiro: 7Letras/PGET, 2007 [1985].

CARVALHO, Luiz Fernando. Entrevista concedida a Natália Castro para realização da matéria "Linguagem universal". O Globo, Rio de Janeiro, 18 mai. 2014. Revista da TV, p. 12-15.

CASTRO, Natália. Linguagem universal. O Globo, Rio de Janeiro, 18 mai. 2014. Revista da TV, p. 12-15. 
DUQUE, Fernando Almeida Mendes. Legendagens comercial e amadora do primeiro episódio da primeira temporada de Game of Thrones. Juiz de Fora: Faculdade de Letras da UFJF, 2014. Monografia de Conclusão do Bacharelado em Letras: Ênfase em Tradução - Inglês.

GERAÇÃO BRASIL. Novela de Filipe Miguez e Izabel de Oliveira. Escrita por Filipe Miguez e Izabel de Oliveira, com a colaboração de Daisy Chaves, Isabel Muniz, João Brandão, Laís Mendes Pimentel, Paula Amaral e Sérgio Marques. Direção: Allan Fiterman, Thiago Teitelroit, Oscar Francisco e Giovanna Machline. Direção geral: Maria de Médicis e Natália Grimberg, sob núcleo de Denise Saraceni. Elenco: Murilo Benício, Cláudia Abreu, Taís Araújo, Renata Sorrah, Isabelle Drummond, Humberto Carrão, Chandelly Braz, Ricardo Tozzi, Dudu Azevedo, Lázaro Ramos, Luís Miranda, Leandro Hassum, GiseleFróes, Titina Medeiros, Luiz Henrique Nogueira, Rodrigo Pandolfo, Felipe Abib e outros. Rio de Janeiro, 19 h., 5 de maio a 31 de outubro de 2014, 155 capítulos, cor.

KOGUT, Patrícia. Nota zero. O Globo, Rio de Janeiro, 14 mai. 2014, Segundo Caderno, p. 8.

. Nota dez. O Globo, Rio de Janeiro, 22 nov. 2014, Segundo Caderno, p. 8.

MEU PEDACINHO DE CHÃO. Novela de Benedito Ruy Barbosa. Escrita por Benedito Ruy Barbosa, com a colaboração de Edilene Barbosa, Edmara Barbosa e Marcos Barbosa. Direção: Henrique Sauer e Pedro Freire. Direção geral: Carlos Araújo e Luiz Fernando Carvalho, sob núcleo de Luiz Fernando Carvalho e Dionísio Azevedo. Elenco: Bruna Linzmeyer, Irandhir Santos, Johnny Massaro, Rodrigo Lombardi, Antônio Fagundes, Osmar Prado, Juliana Paes, Paula Barbosa, Geytsa Garcia, Tomás Sampaio, Cintia Dicker, Inês Peixoto, Bruno Fagundes, Dani Ornellas, Letícia Almeida, Ricardo Blat e outros. Rio de janeiro, 18 h., 7 de abril a 1 de agosto de 2014, 96 capítulos, cor.

MIGUEZ, Filipe. Entrevista concedida a Natália Castro para realização da matéria "Linguagem universal". O Globo, Rio de Janeiro, 18 mai. 2014. Revista da TV, p. 12-15.

NORONHA, Felipe Augusto. A legendagem de trechos de episódios da série The Office em língua portuguesa do Brasil encontrada na Internet: no- 
va mídia, novos procedimentos. Juiz de Fora: Faculdade de Letras da UFJF, 2010. Monografia de Conclusão do Bacharelado em Letras: Ênfase em Tradução - Inglês.

OLIVEIRA, Izabel. Entrevista concedida a Natália Castro para realização da matéria "Linguagem universal". O Globo, Rio de Janeiro, 18 mai. 2014. Revista da TV, p. 12-15.

OLIVEIRA, Maria Clara Castellões de. Questões éticas e políticas em torno da tradução literária. Tradução em Revista, v. 7, p. 1-10, 2009. Disponível em: $<$ http://www.maxwell.vrac.puc-rio.br/trad_em_revista. php? strSecao=input 0 >. Acesso em 20 nov. 2014.

."A construção das éticas de tradução de textos Literários a partir

da experiência: A interação entre a academia e a sociedade". Gragoatá, v. 31, p. 97-106, 2011. Disponível em

http://www.uff.br/revistagragoata/revistas/gragoata31web.pdf. Acessado em 20 nov. 2014.

Resumo: Este trabalho apresenta uma reflexão acerca dos movimentos que, no âmbito de produções midiáticas, podem vir a ter influência sobre a prática da tradução literária. São discutidas as estratégias linguísticas encontradas nas novelas Meu Pedacinho de Chão e Geração Brasil, da Rede Globo, que se aproximam de procedimentos de tradução estrangeirizantes. Investiga-se, ainda, como legendas feitas e disponibilizadas na Internet por fãs de algumas séries de TV alargam os limites da legendagem, uma vez que se pautam em procedimentos semelhantes à tradução da letra, tal como defendeu Antoine Berman em A Tradução e a Letra ou o Albergue do Longínquo (2007 [1985]).

Abstract: This paper reflects on processes within media productions which may influence literary translation practice. We discuss language strategies found in Meu Pedacinho de Chão and Geração Brasil, soap operas by Rede Globo, which are similar to foreignizing translation procedures. We also investigate the way subtitles created and made available on the Internet by fans of certain TV series widen the limits of subtitling, as they are based on 
OLIVEIRA Produções midiáticas contemporâneas e a ampliação dos limites da tradução

procedures similar to the "labor on the letter", advocated by Antoine Berman in A Tradução e a Letra ou o Albergue do Longínquo (2007 [1985]). 